\title{
Temporal and spatial relationships between segmentation and homeotic gene expression in Drosophila embryos: distributions of the fushi tarazu, engrailed, Sex combs reduced, Antennapedia, and Ultrabithorax proteins
}

\author{
Sean B. Carroll ${ }^{1,4}$ Stephen DiNardo, ${ }^{2}$ Patrick H. O'Farrell, ${ }^{2}$ Robert A.H. White, ${ }^{3}$ and \\ Matthew P. Scott ${ }^{1,5}$ \\ ${ }^{1}$ Department of Molecular, Cellular, and Developmental Biology, University of Colorado, Boulder, Colorado 80309-0347 USA; \\ 2Department of Biochemistry and Biophysics, University of California, San Francisco Medical School, San Francisco, \\ California 94143 USA; $^{3}$ Department of Anatomy, University of Cambridge, Cambridge CB2 3DY, England
}

The specification of segment number and identity in the Drosophila embryo requires the activity of several classes of genes that may be grouped according to the array of pattern elements that they control. Double-label immunofluorescence was used to simultaneously localize the products of genes representative of the pair-rule segmentation class (fushi tarazu), the segment polarity class (engrailed), and the homeotic class (Sex combs reduced, Antennapedia, and Ultrabithorax) of pattern-regulating genes. The temporal order of appearance of each class of proteins and the precise spatial relationships between the products of the different genes are described with single-cell resolution. Boundaries of gene expression, particularly the parasegmental boundaries, are established by early-acting genes such as fushi tarazu and subsequently respected by the expression patterns of later appearing gene products such as engrailed and Ultrabithorax, suggesting regulatory relationships between certain pairs of genes. In addition, the dynamic transitions observed in spatial relationship among the Sex combs reduced, Antennapedia, and Ultrabithorax homeotic protein patterns during the early period of embryogenesis may reflect cross-regulatory interactions among these genes. Finally, some cells contain a single homeotic product, whereas other cells simultaneously contain several, suggesting that certain cells may be determined by the combinatorial action of homeotic genes.

[Key Words: Homeotic; segmentation; Drosophila; embryogenesis]

Received September 10, 1987; revised version accepted January 18, 1988.

The development of the Drosophila embryonic body pattern is dependent upon a hierarchy of sequentially activated zygotic genes. At least four gene classes that regulate anterior-posterior differentiation of the embryo have been distinguished by the pattern of defects observed in mutants (Nüsslein-Volhard and Wieschaus 1980). Each of the gene classes (gap, pair-rule, segment polarity, and homeotic) is expressed in characteristic spatial arrays of cells within the primordia of the segments whose development they control (reviewed in Akam 1987; Scott and Carroll 1987). Analyses of mutants have revealed that these striking patterns of gene expression are controlled by a network of regulatory interactions among the four classes of genes. In a given

${ }^{4}$ Present address: Laboratory of Molecular Biology, University of Wisconsin-Madison, Madison, Wisconsin 53706 USA.

${ }^{5}$ To whom requests for reprints should be addressed. class, genes are regulated by the action of genes that are expressed earlier and by other specific genes within the same class. To understand the operation of this network of regulatory interactions, we need to know how the spatial and temporal expression of each gene relates to the others. Although the RNA transcript or protein distributions have now been analyzed for several genes, few have been examined in relation to each other with single-cell resolution to allow a precise description of the boundaries of gene expression and the determination of whether multiple genes are expressed within cells.

With the production of antibody probes for several different proteins representative of most of the recognized classes of early-acting genes controlling pattern formation, it is possible to define more precisely the dynamics of protein product accumulation and the boundaries between the spatial domains of gene products acting 
during the same period of embryogenesis. Here we present comparative data on the expression of a pairrule segmentation gene, fushi tarazu (ftz), which directs the formation of alternate parasegments (PS) (Wakimoto and Kaufman 1981; Jürgens et al. 1984); a segment polarity gene, engrailed (en), which defines the posterior compartment of each segment (Morata and Lawrence 1975; Kornberg 1981a,b; Kornberg et al. 1985); and the homeotic genes, Sex combs reduced (Scr), Antennapedia (Antp), and Ultrabithorax (Ubx), which have their major effects on the identity of the labial and first thoracic (Wakimoto and Kaufman 1981; Sato et al. 1985), first through third thoracic (Wakimoto and Kaufman 1981; Sato et al. 1985), and posterior thoracic and first abdominal segments (Lewis 1978), respectively.

In several cases we observe sharp boundaries of gene expression that correspond to parasegmental boundaries. However, there are significant cases where boundaries do not coincide with parasegmental borders. The patterns of expression are quite dynamic. In some cases, initially sharp boundaries become less distinct over time, and in other cases, expression patterns sharpen to respect borders more precisely. Clearly, there are cases where multiple regulatory gene products are present in the same cell. This is discussed in terms of combinatorial models for cell fate determination.

\section{Results \\ Localization of proteins in whole mount Drosophila embryos}

All of the experiments described in this work involve indirect immunofluorescence analysis of doubly or triply labeled whole-mount embryos. The embryos were prepared by formaldehyde fixation in heptane and devitellinized with methanol/heptane, as described previously (Carroll and Scott 1985; DiNardo et al. 1985; Karr and Alberts 1986). This technique affords visualization of most cells of the embryo with excellent preservation of morphology. We focus upon expression of the proteins in the simplest and most accessible two-dimensional cell layer, the early embryonic ectoderm, thus avoiding the complexities inherent in more complex arrays of cells (e.g., the nervous system at later stages). However, all of the genes studied are also expressed in the nervous system, and the relationships between gene expression patterns may be different in different tissues (Akam and Martinez-Arias 1985; Martinez-Arias et al. 1987). The wild-type patterns of each individual protein have been described previously, though generally not in comparison with any other products. The proteins are encoded by $f t z$ (Carroll and Scott 1985), en (DiNardo et al. 1985), Scr (Riley et al. 1987; Mahaffey and Kaufman 1987), Antp (Carroll et al. 1986; Wirz et al. 1986) and Ubx (White and Wilcox 1984, 1895a; Beachy et al. 1985); the antibody preparations used are described in the first references given in each case. In addition, a monoclonal antibody that detects $S c r$ protein was kindly provided by M. Glicksman and D. Brower (manuscript submitted).
The temporal and spatial relationship between the expression of the $\mathrm{ftz}$ pair-rule gene and the en segment polarity gene

The $f t z$ protein is first detectable by immunofluorescence in a series of evenly spaced stripes encircling the embryo during cellularization (Carroll and Scott 1985). By the time of completion of cellularization and initiation of gastrulation, the $f t z$ stripes have changed from about four nuclei in width to three. At the earliest time en protein is detected (Fig. $1 \mathrm{~b}$ ), the $f t z$ stripes have already shrunk (Fig. 1a). Thus, the mature pattern of $f t z$ expression is observed before the en pattern has fully appeared. The initial 14 stripes of en protein appear in an ordered sequence, beginning with the second stripe (corresponding to the posterior cells of the maxillary segment) and following in a progression of even-numbered stripes that are more strongly labeled than the odd-numbered stripes in an anterior-to-posterior gradient (DiNardo et al. 1985; Weir and Kornberg 1985, Fig. 1b). The en stripes are one to two cells wide as they develop. As noted previously, the level of en antigen varies among different cells within a given en stripe as the stripe develops, resulting in a ragged appearance (DiNardo et al. 1985). Doubly labeled embryos reveal the superposition of the even-numbered $e n$ stripes with each $f t z$ stripe (Fig. la,b). In analyzing seven doubly labeled embryos, we find that greater than $92 \%(374 / 405)$ of the cells accumulating en in even numbered stripes are coincident with cells at the anterior edge of the ftz stripe (Fig. 1c,d). In $2 \%$ of the cases, a $f t z$ expressing cell lies anterior to an $e n$-expressing cell. Given the low level of $e n$ antigen and the ragged appearance of en stripes at this early stage, these few cases may either be true exceptions or cases where en induction has not proceeded far enough to detect the protein in the anterior most cell. The remaining $6 \%(23 / 405)$ of $e n$-expressing cells are in the (few) areas where the developing en stripes seem to be two cells wide rather than one cell wide. In these cases, the first en-expressing cell is still coincident with a cell at the anterior border of the $f t z$ stripe. Significantly, we have not observed any cases where an en-expressing cell lies anterior to the $f t z$ stripe. Because en expression marks the anterior boundaries of PS (Martinez-Arias and Lawrence 1985), the anterior edge of each three-cellwide $f t z$ stripe is at the parasegmental boundary. The boundaries of the original four-cell-wide $f t z$ stripe cannot be determined directly as we are examining the $f t z$ stripes during a period when they are progressively narrowing. Based upon the presence of weakly labeled nuclei at the posterior edge of each $\mathrm{ftz}$ stripe and, in contrast, the sharp boundary between expressing and nonexpressing cells at the anterior edge, we suggest that $f t z$ expression is lost progressively from the posterior edge of each stripe. Therefore, the anterior edge of the fourcell-wide stripe is at the parasegmental boundary. Lawrence et al. (1987) have also concluded that the fourcell-wide $f t z$ stripes are parasegmental by marking cells with $\beta$-galactosidase under $f t z$ promoter control (Hiromi et al. 1985).

$f t z$ protein vanishes before it is possible to detect any 


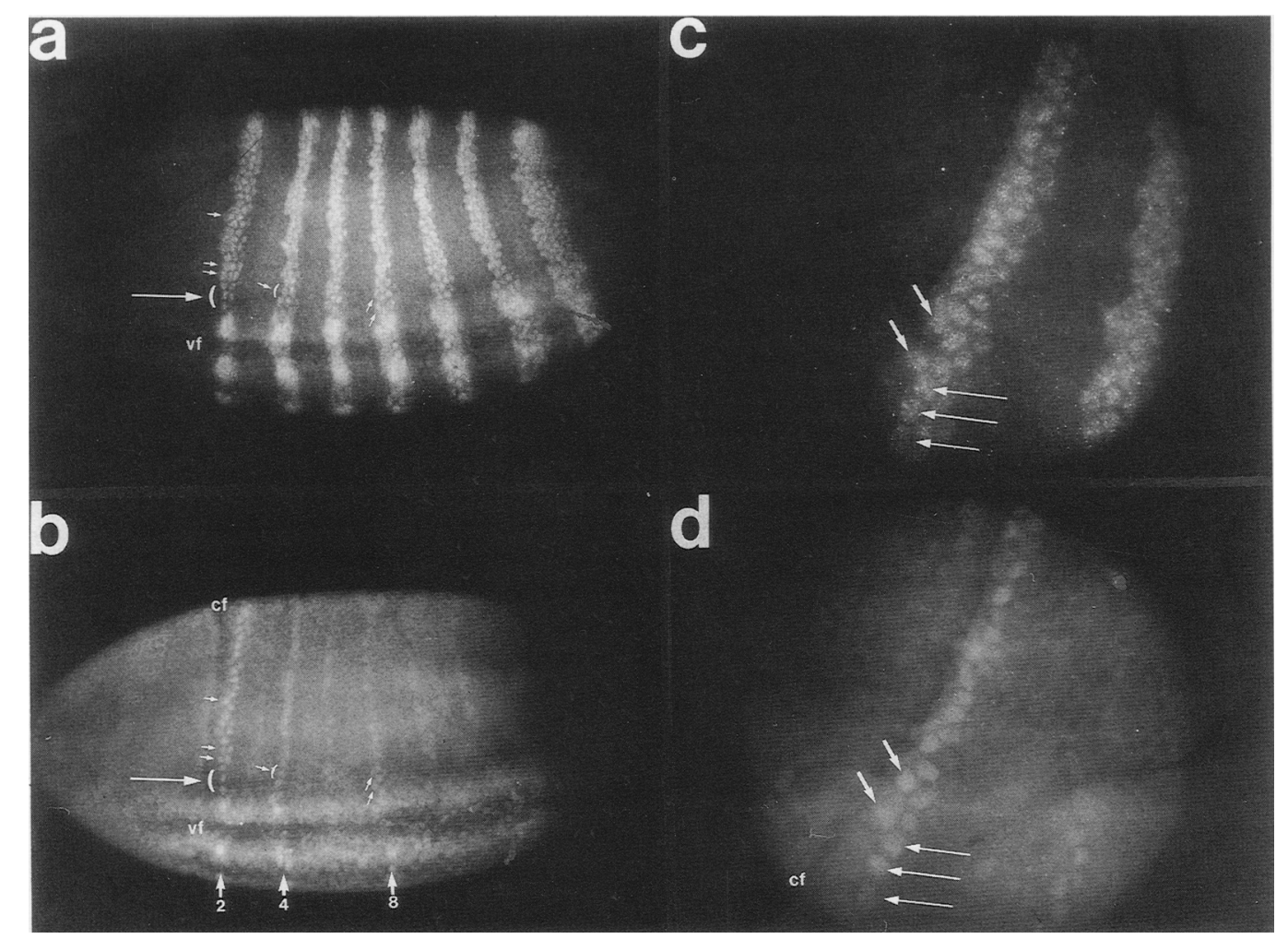

Figure 1. engrailed expression is coincident with the leading edge of each $\mathrm{ftz}$ protein stripe. Wild-type embryos were doubly labeled with a rabbit polyclonal antibody against $f t z$ protein $(a, c)$ and a mouse polyclonal en antibody $(b, d)$. The embryo in each case $(a, b$ are one embryo; $c, d$ are another) has just begun gastrulation; the ventral (vf in $a, b)$ and cephalic (cf in $b, d)$ furrows are evident. The most anterior en stripe (stripe 1) has not yet appeared, nor have the most posterior ones. The ftz stripes have already been reduced in width from about four cells to about three. The even-numbered en stripes overlap with the $f t z$ stripes. The level of engrailed protein accumulation at this stage is such that the overlap between $f t z$ and $e n$ is most clear for stripes 2,4 , and $8(b)$. The long arrow and bracket indicate the position of three nuclei that express both $f t z|a|$ and $e n|b|$. Other nuclei exhibiting both $f t z$ and en staining are indicated in corresponding panels by smaller arrows or a small arrow with a bracket (e.g., the fourth en stripe and second $f t z$ stripe in $a, b)$. A higher magnification view of a double-labeled embryo is shown in $c$ and $d$. The region shown is part of the most anterior $f t z$ stripe (c) and the corresponding second $e n$ stripe (d). Arrows indicate cells exhibiting coincident $e n$ and $f t z$ expression at the anterior edge of the $f t z$ stripe.

of the three homeotic proteins studied here. $f t z$ protein is detectable in the embryonic ectoderm during the period of germ-band elongation when each segment primordium is roughly four cells wide, but the homeotic proteins first appear only after the cell movements and cell divisions have taken place that increase the number of cells per segment. The en protein continues to accumulate during germ-band elongation and is therefore present at the same time as the homeotic proteins. The en protein is thought to define the posterior compartment of segment primordia and helps in analyzing the distribution of homeotic proteins.

Expression of the homeotic gene Ubx respects the boundaries established by earlier acting segmentation genes

$U b x$ protein is detected in the posterior thoracic $(T)$ and in the abdominal (A) segments in a relatively complex pattern (White and Wilcox 1985a). Ubx, Scr, and Antp proteins appear at approximately the same time (see below/-while the germ band is elongating. In general, the $U b x$ pattern of expression respects domains established by the segmentation gene products quite precisely. en domains of expression are coincident with or delimit most of the $U b x$ domains.

The most anterior block of high-level Ubx expression is PS 6 (Fig. 2b,d), which is composed of pT3 and aAl. The anterior PS 6 cells, i.e., the posterior third thoracic cells, contain both en protein (Fig. $2 \mathrm{a}, \mathrm{c}$ ) and $U b x$ protein. The level of $U b x$ expression is somewhat variable in the ventral pT3 cells that express en and is lower on average relative to anterior $\mathrm{Al}$ (Fig. 2c,d). In more lateral regions of pT3, $U b x$ and en expression are still coincident, but the $U b \mathrm{x}$ protein level more closely approximates the level reached in A1. There is a sharp transition between high-level $U b x$ expression and much reduced $U b x$ expression, coincident with the anterior edge of the en stripe in pAl, which defines the anterior limit of PS 7 (black arrowhead, Fig. 2c,d). In the more posterior abdominal segments, A2-A7, Ubx protein is present and graded from lower to higher expression through the anterior compartment of each developing segment (Fig. 2b). In each of these abdominal primordia, the patterns of 


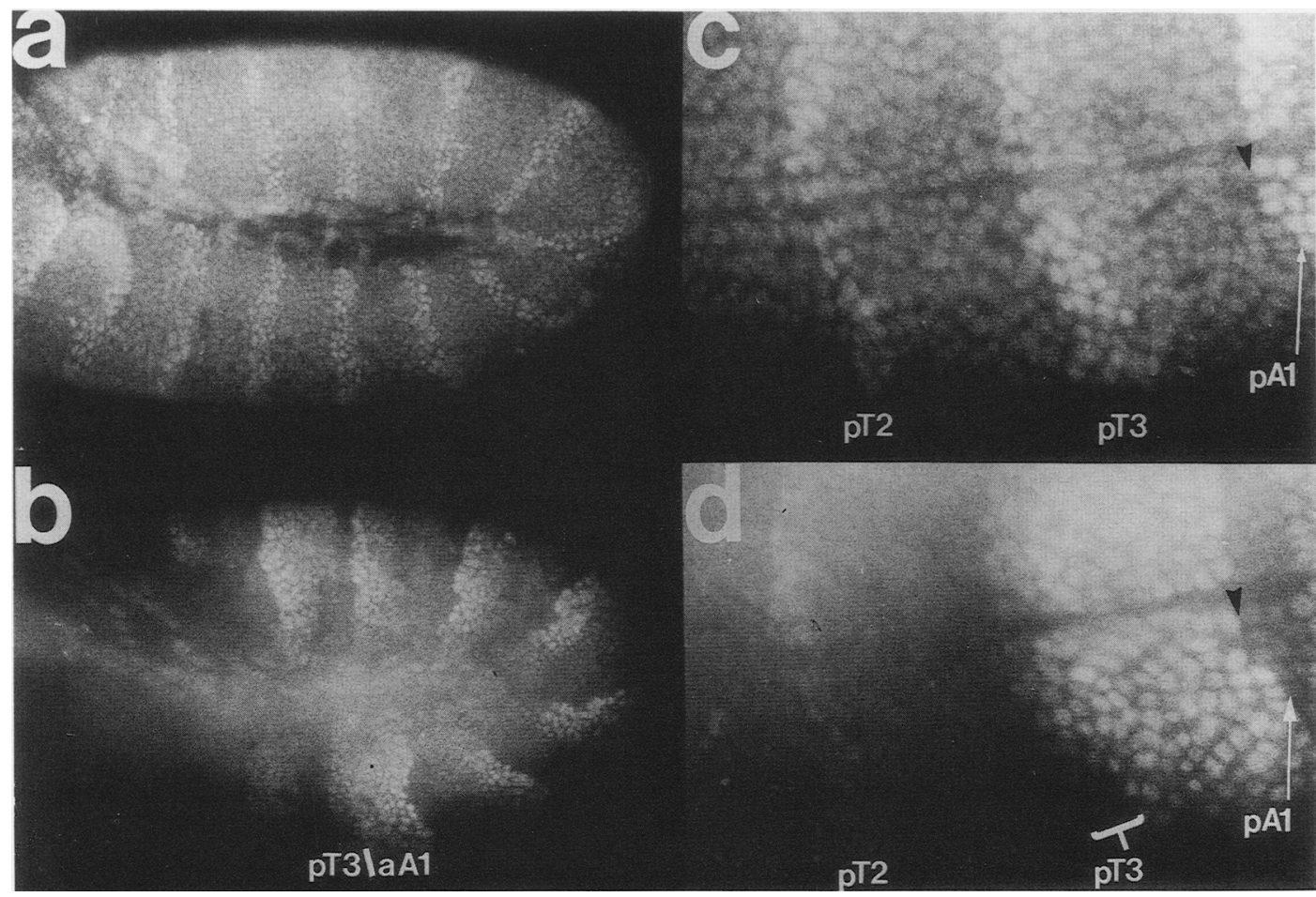

Figure 2. The spatial domain of Ultrabithorax protein expression in relation to engrailed protein expression. Wild-type embryos were doubly labeled with antibodies to en $(a, c)$ and $U b x(b, d) .(a, b)$ A wild-type extended germ-band-stage embryo. The position of the broad PS $6 U b x$ domain (posterior T3/anterior A1) is indicated in $b$. Note that expression of $U b x$ is weaker in posterior T3 than in anterior $\mathrm{A} 1$ (see also $d$ ). (c,d) Higher magnification view of an embryo at the same stage as $a, b$. The relationship between $U b x$ and $e n$ expression in the posterior thoracic and anterior abdominal primordia is highlighted. Low-level $U b x$ expression is coincident with en expression in posterior T2 and posterior T3. High-level expression of $U b x$ in the anterior compartments of the abdominal segments is interrupted by cells that are strongly labeled by en antibody and weakly labeled by $U b x$ antibody. The black arrow is in precisely the same position in $c$ and $d$, at a boundary between cells containing $U b x$ protein and those containing en protein.

$U b x$ and en are complementary, with en protein in all cells of the posterior compartments and $U b x$ protein in all cells of the anterior compartments. In contrast, $U b x$ expression coincides with en expression in pT2 (Fig. $2 \mathrm{c}, \mathrm{d})$. As in $\mathrm{pT} 3, U b \mathrm{~b}$ protein is at low levels in pT2 mid-ventrally, and slightly higher levels dorsolaterally. At dorsolateral positions, $U b x$ protein is not restricted to en-containing cells but extends into aT3 (Fig. 4a,c).

\section{The spatial domain of Scr protein expression}

Scr protein begins to accumulate at high levels in an anterior patch of cells during germ band extension after the cells of the ectoderm have resumed division (Riley et al. 1987). Along the ventral midline, this early patch of $S \mathrm{Cr}$ protein expression is about $9-10$ cells wide (Fig. 3a). By double labeling embryos with an anti-en antibody, it can be seen that high-level $S c r$ expression at this stage is restricted to PS 2 and to some dorsolateral cells of PS 3, with only a trace of $S c r$ protein midventrally in PS 3 (Fig. $3 \mathrm{a}, \mathrm{b})$. PS 3 expression of $S c r$ increases during germ-band shortening to moderately high levels, though not quite to the level of the $S c r$ protein in PS 2 (Fig. 3c). The boundaries of $\mathrm{Scr}$ expression in shortened germ-band embryos, when the grooves in the embryo demarcate segments rather than PS, was determined by double staining with en antibodies (Fig. 3c,d). Along the ventral midline, the most anterior cells that contain $S c r$ protein continue to coincide with the posterior maxillary segment cells that express en protein (Fig. 3c,d, brackets with solid arrows) thus respecting a parasegmental boundary. The posterior boundary of high-level Scr expression extends through anterior $\mathrm{T} 1$. The boundaries are not as distinct at more lateral positions. For example, the $S c r$ protein level is low or absent in the lateral cells of the posterior maxillary compartment (Fig. 3c, asterisk). In addition, Scr is present in some of the posterior cells of the first thoracic segment (Fig. 3c,d, open arrows). Thus, like $U b x$ in aT3, Scr does not strictly obey compartmental boundaries at all positions in the embryo.

Dynamic changes in the expression of the Scr. Antp, and Ubx proteins

The homeotic proteins studied here appear with virtually identical kinetics. However, as has been shown here and elsewhere (Carroll et al. 1986; White and Lehmann 1986; Mahaffey and Kaufman 1987; Riley et al. 1987), there are significant transitions in homeotic protein patterns during mid embryogenesis. We have used triple labeling of embryos with murine monoclonal anti- 
bodies against $S c r$ and $U b x$ proteins and polyclonal rabbit antibodies against Antp protein to simultaneously detect all three antigens during the pattern changes.

Figure $4 a-d$, shows the early pattern of homeotic proteins while the germ band is fully extended. There is strong $S c r$ expression in PS 2 and in the most lateral parts of PS 3. Scr is expressed at relatively low levels throughout the rest of PS 3 (Fig. 4a). Ubx is expressed strongly in PS 6, particularly in aAl, and in the more posterior abdominal primordia (see description above). $U b x$ is expressed at relatively low levels in PS 5 . Ventrally, the PS 5 expression of $U b x$ is limited to those cells that also express en in pT2 (Fig. 2c,d). At more lateral positions, $U b x$ expression extends posteriorly into cells that do not express en and, therefore, into anterior T3. PS 4 has no detectable expression of either Scr or $U b x$ but, along with PS 5, contains a high level of Antp protein (Fig. 4b,d). There is also low-level Antp protein in PS 3 and a moderate to high level in some cells in PS 6. By comparing the $S c r$ and $U b x$ patterns with the Antp pattern, (Fig. 4a vs. b; c vs. d), it can be seen that there are cells that contain only one homeotic protein, cells with low levels of two gene products, and cells with moderate levels of two or three (including en) gene products, but no cells that contain two homeotic proteins at high levels.

For example, the cells of PS 4, where $S c r$ and $U b x$ are inactive, express Antp at high levels (Fig. 4a,b; c,d). Cells of PS 3 have low levels of both $S c r$ and Antp (Fig. 4c,d). Although a substantial number of PS 5 cells have Antp but no $U b x$ expression, cells that mark the anterior edge of PS 5 ventrally and a large part of PS 5 laterally express both $U b x$ and Antp at moderate levels. Antp and $U b x$ are also both expressed in the ventral cells that mark the anterior of PS 6 (Fig. 4c,d), where cells also express $e n$; therefore, pT2 and pT3 contain Antp, $U b x$, and en proteins.

Figure $4 \mathrm{e}-\mathrm{h}$ display the patterns of homeotic protein expression after the significant transitions that occur during germ-band shortening. At this stage, $S C r$ is on strongly in PS 3, and Antp expression is largely confined to most of PS 4 and PS 5 . In some cases, the transitions from patterns observed at the germ-band extension stage to the shortened germ-band stage seem to reflect the known cross-regulatory properties of the homeotic proteins. For example, $U b x$ functions to negatively regulate Antp in PS 5 and PS 6 (Hafen et al. 1984; Harding et al. 1985; Carroll et al. 1986). We find that Ubx expression

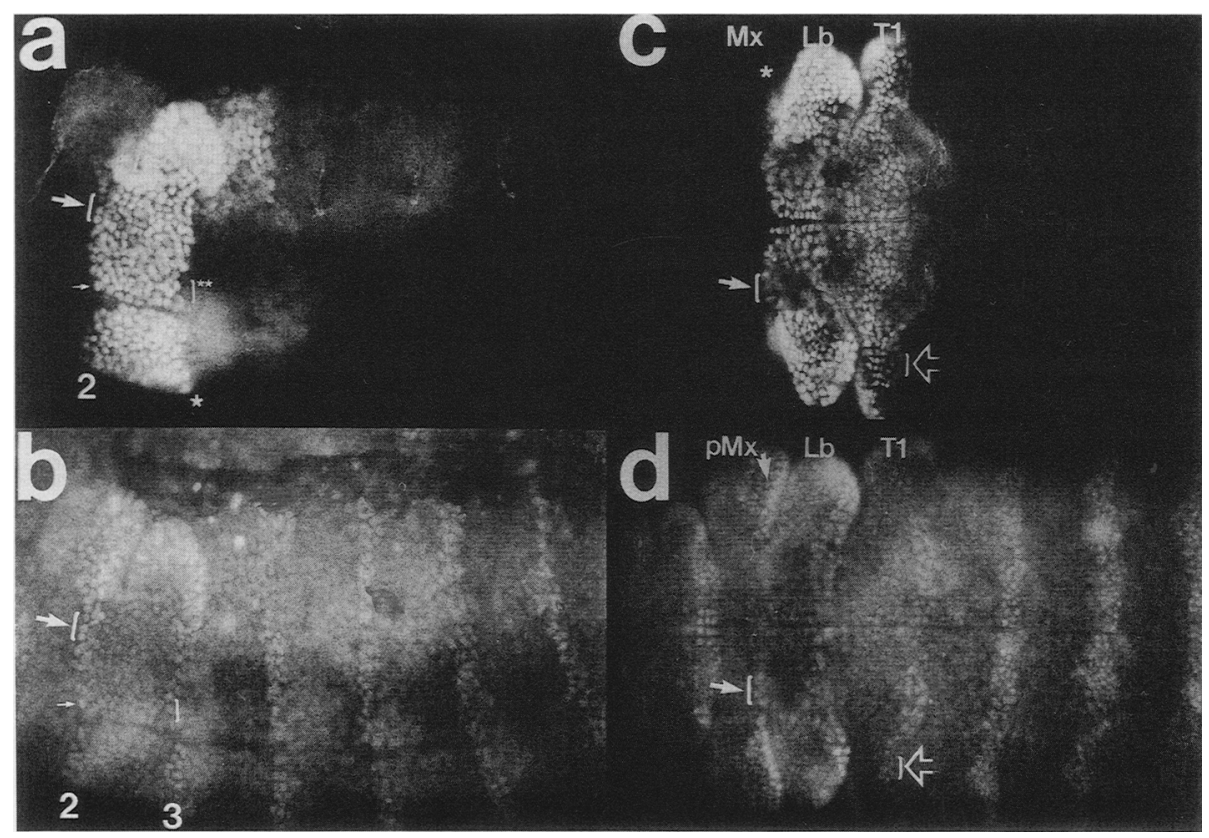

Figure 3. The spatial domain of $S c r$ protein expression in relation to en protein expression. Wild-type embryos were doubly labeled with a rabbit polyclonal antibody against $S c r(a, c)$ and a mouse polyclonal antibody against en protein $(b, c)$. $(a, b)$ A wild-type embryo at the germ-band extension stage exhibiting the early pattern of $S c r$ is shown in $a$. Using the en stripes of the same embryo $(b)$ as a reference, it can be seen that strong $S c r$ expression along the ventral midline extends from the second en stripe (the posterior compartment of the maxillary segment) through the anterior compartment of the labial segment up to the edge of the third en stripe (thus, all of PS 2). The arrows indicate examples of coincident staining of Scr and en. The bracket and asterisk indicate the position of very weakly labeled cells in the posterior labial segment. (c,d) A wild-type embryo with a shortening germ band exhibiting the later pattern of Scr expression. Scr expression along the midline extends two PS (PS 2 and PS 3 ) in length, from the posterior compartment of the maxillary segment through the anterior compartment of the first thoracic segment. The solid arrows with brackets indicate three cells in the posterior maxillary segment (anterior PS 2) that contain both proteins. The asterisk in $c$ indicates that $S c r$ expression at more lateral positions does not fill the entire posterior maxillary segment compartment, based on the identification of those posterior compartment cells by $e n$ in $d$. Scr expression at lateral positions in T1 does extend at moderate levels into the posterior compartment (open arrows with brackets in $c$ and $d$ ). In panels $b$ and $d$, the out-of-focus signal at the lateral edges of the labial lobe is due to en-expressing cells that are migrating underneath the lobe and will form the dorsal ridge. 
Figure 4. The spatial relationship between $S c r$, $A n t p$, and $U b x$ protein expression. Wild-type embryos were triply labeled with mouse monoclonal antibodies against $S c r$ and $U b x$ and a rabbit polyclonal antibody against $A n t p$. The $S c r$ and $U b x$ domains are separated by the Antp domain so that the two monoclonal antibody patterns can be distinguished. $(a-d)$ Wild-type extended germ-band-stage embryos exhibiting the early patterns of homeotic gene expression over the thoracic and anterior abdominal segment primordia. $a$ and $b$ are the same embryo; $c$ and $d$ are the same embryo. Along the ventral midline, high-level Scr expression extends over PS 2. Antp expression extends from the posterior labial (PS 3) through the posterior third thoracic segment. $U b x$ expression is at low levels in part of posterior T2 and in posterior T3 and at high levels in the anterior compartments of the abdominal segments. Scr $(c)$ and Antp (d) expression, both at very low levels, overlap in anterior T1. Antp $(d)$ and $U b x(c)$ expression overlap in posterior T2 (arrow with bracket) and in posterior T3 (arrow with bracket), both places where $U b x$ expression is low. $(e-h)$ Wild-type shortened germ-band embryos exhibiting late patterns of homeotic gene expression. $e$ and $f$ are the same embryo; $g$ and $h$ are another embryo. $S c r$, Antp, and $U b x$ protein expression appear to be largely mutually exclusive across the thorax; most cells contain only one of the proteins. Note the absence of Antp expression laterally in T2 and T3 in areas filled by $U b x$ (e,f, arrows). $S c r$ expression at this stage extends posteriorly through anterior T1 along the midline (e,g, solid arrows). The outof-focus bright cloud (h) is due to Antp fluorescence out of the focal plane in the ventral nervous system (vns). The small arrows in $g$ and $h$ indicate the positions of the segmental folds separating $\mathrm{T} 1$ from $\mathrm{T} 2$ and $\mathrm{T} 2$ from $\mathrm{T} 3$.

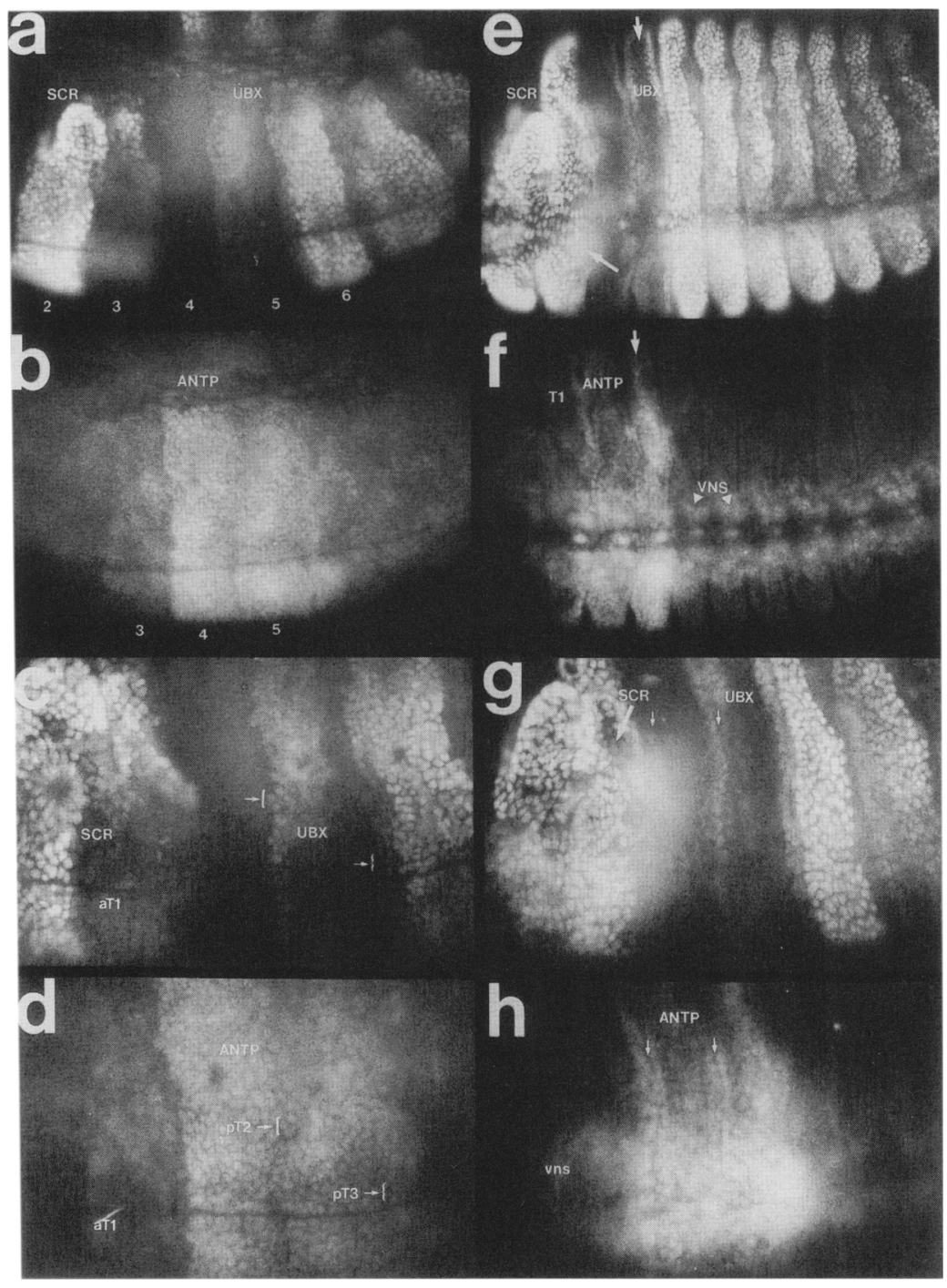

expands laterally during germ-band shortening in $\mathrm{pT} 2$ and pT3, the anterior boundaries of PS 5 and PS 6, respectively. This expansion is concomitant with a repression in Antp expression (Fig. 4e,f). As a result of these transitions in homeotic protein patterns, there are fewer cases later in embryogenesis where single cells express more than one homeotic protein, although $U b x$ and Antp (and en, Fig. 2) continue to be present simultaneously in some cells within pT2 (Fig. 4g,h).

\section{Discussion}

\section{A temporal hierarchy of regulatory gene expression}

The sequence and pattern of expression of the regulatory proteins studied here are depicted schematically in Figure 5, covering the first $10 \mathrm{hr}$ (approximately half) of Drosophila embryogenesis. The time of appearance of the protein products from each class of regulatory genes reflects what is now known about the regulation of genes in each class by earlier acting genes. For example, it is known that $f t z$ controls aspects of $e n$ and homeotic gene expression (Duncan 1986; Howard and Ingham 1986; Ingham and Martinez-Arias 1986; DiNardo and O'Farrell 1987), which is consistent with the presence of $\mathrm{ftz}$ protein before the protein patterns of the other genes emerge.

\section{A cell-for-cell correspondence in expression between sequentially activated genes may reveal regulatory relationships}

We have observed several instances where a border of expression for a particular gene coincides cell for cell with the boundary of expression of a gene expressed at a preceding step in the hierarchy. The length of such boundaries, coextensive for many cells, argues that the earlier appearing gene product regulates the next. Although we cannot rule out the possibility that both genes respond to some other common factor along the coextensive boundary, there are several cases where coincident expression is likely to be due to direct regulatory interactions. For example, quite precise boundaries are established at the anterior edge of each $f t z$ stripe. The 
developing even-numbered en stripes largely coincide with these boundaries. The rare exceptions may represent true 'mistakes' in patterning or may be an unavoidable limitation of analyzing a very dynamic process (the evolution of spatial gene expression patterns) using fixed preparations. Significantly, we only observe en expression in cells that are also expressing $f t z$. This overlap in
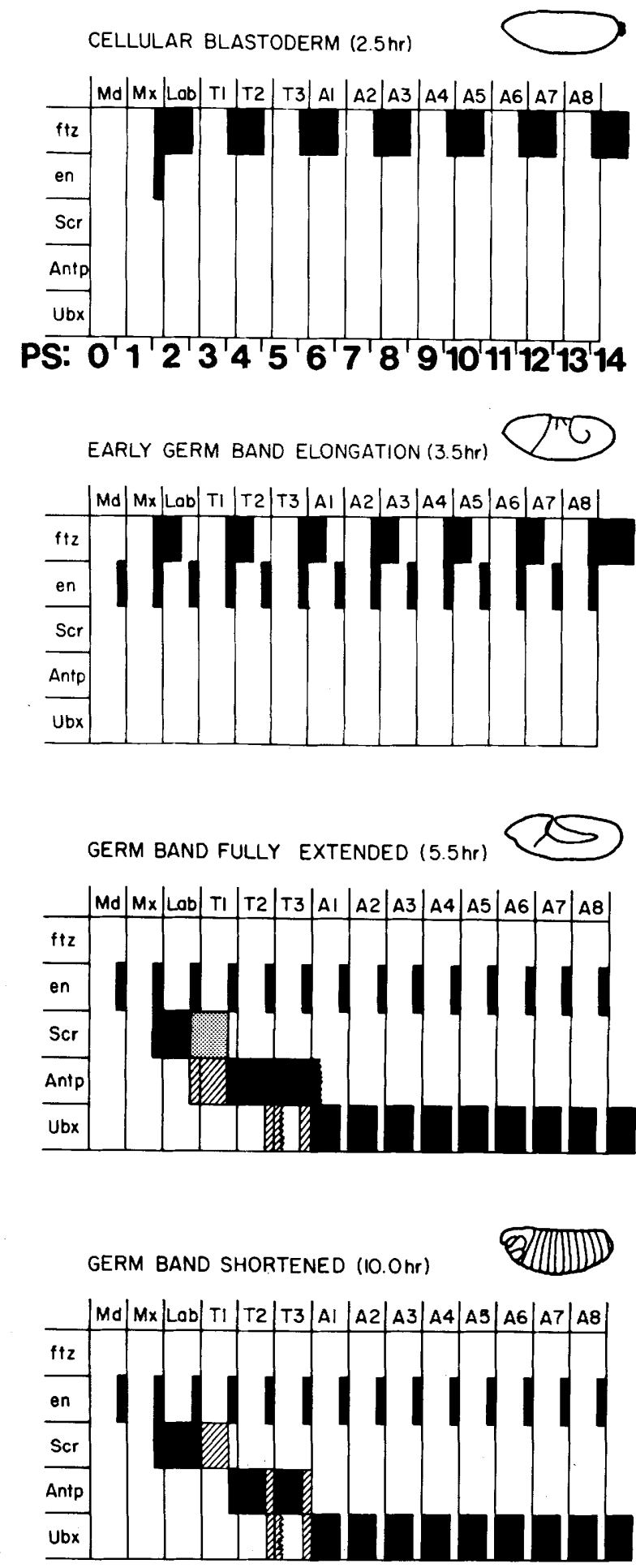

$e n$ and $f t z$ expression is consistent with the requirement for $f t z$ activity in the production of even-numbered en stripes (Howard and Ingham 1986). Thus, the en pattern is a good example of a downstream gene responding precisely to the boundaries established by earlier acting regulatory genes.

In addition, there is evidence that $f t z$ activity is required for the proper activation of homeotic genes in even-numbered PS (Ingham and Martinez-Arias 1986). For example, the peak of $U b x$ expression in PS 6 depends on $f t z$. Because $U b x$ expression precisely fills the PS 6 domain as determined using en-expressing cells as markers, there is a coincidence between cells that express $f t z$ at early stages and cells that express $U b x$ later. The coextensive nature of these two expression patterns is consistent with the possibility that the $f t z$ protein directly regulates $U b x$.

Furthermore, a generalization is suggested: Coincident gene expression patterns observed by carefully mapping the boundaries of expression for two genes suggest a regulatory relationship between those genes. Thus, precise cell-by-cell comparisons are likely to continue to contribute to the elucidation of regulatory circuitry.

\section{One boundary of expression often respected by homeotic genes is the parasegmental border}

In examining the various patterns of protein expression, we note that some are sharp and relatively stable and others are not. For example, the anterior edge of each $f t z$ stripe stands out well against background staining and persists until $\mathrm{ftz}$ protein disappears during germ-band elongation. In contrast, the posterior of each $f t z$ stripe 'moves' as the stripe narrows / see also Lawrence et al. 1987). The anterior boundary of $f t z$ stripes defines the leading edge of each even-numbered parasegmental unit (Martinez-Arias and Lawrence 1985). The parasegmental border is associated with a known enduring distinction in the behavior of cells, as subsequent domains of regulatory gene expression respect this border precisely. Not only is this border respected by the developing en stripe,

Figure 5. Schematic representation of the temporal order and spatial relationship of $f t z$, en, $S c r, A n t p$ and $U b x$ protein expression during embryonic development. Summary of data from previous figures emphasizing the sequence of changes in the ectodermal expression of the segmentation and homeotic genes. The ventral midline has been used as a common reference point to simplify the presentation; the distribution of proteins is different in many cases away from the ventral midline. The segmental position of high levels of protein expression is indicated by solid black shading and lower levels by hatching. The time and stage of development are indicated at the top of each panel. In some places, homeotic gene expression does not exhibit sharp discontinuities corresponding to en-expression boundaries (e.g., in PS 5, Ubx is not always coincident with en expression). These patterns are represented by wiggly lines. The homeotic protein patterns diagramed are correct for the epidermis only. The mesoderm and neural protein patterns may be quite different. 
but to a large extent, the anterior and posterior extents of homeotic gene expression are defined by parasegmental borders $(U b \mathrm{~b}$ expression extends precisely to the boundary of PS 5 and PS $6 ;$ Scr is expressed up to the anterior edge of PS 2 ventrally; $U b x$ expression is delimited by the posterior borders of PS 6-PS 13). The parasegmental boundary appears to be formed by regulatory interactions that establish, first, discontinuities in patterns of gene expression (probably among the pair-rule genes) and, then, a heritable distinction between cells of adjacent parasegments. The regulation of $e n$ by $f t z$ could be one step in the maintenance of the parasegmental boundary. The knowledge that the anterior border of $f t z$ is important leaves open the question of whether $f t z$ expression is also important in more posterior cells in each $\mathrm{ftz}$ stripe. Some of the answer is likely to come from the analysis of possible $f t z$ regulation of segment polarity genes, such as gooseberry (Bopp et al. 1986) and wingless (Baker 1987), which are expressed in narrow stripes like $e n$, but, at least in the case of wingless, in different cells. If $f t z$ is also regulating these other genes, then $f t z$ expression is important not only to demarcate PS but also to control gene expression in cells in the more posterior parts of the $f t z$ stripes.

\section{Boundaries other than parasegmental borders are also observed}

In particular instances, the spatial domains of homeotic gene expression initiate and terminate away from the parasegmental border. For example, the anterior limit of the Scr expression domain lies at the PS 2 border ventrally (i.e., respects parasegmental borders ventrally) but begins posterior to this border at more dorsolateral positions. The Scr domain also extends beyond the PS 2 boundary partway into PS 3 , again in dorsolateral regions. These positions for the boundaries of expression seem quite precise and reproducible but do not correspond to morphological boundaries, such as the segment border. Genes that control dorsoventral differentiation (e.g., Anderson and Nüsslein-Volhard 1984) may therefore cause genes such as $S c r$ to be expressed in domains with different anterior and posterior limits, depending upon the position of the cells along the dorsoventral axis. To accomplish this, the dorsoventral control genes may need to affect how $S c r$ responds to regulatory inputs from anterior-posterior segmentation gene regulators. We expect that 'downstream' genes exist that are under the control of $S c r$ and that respect the nonparasegmental boundaries apparent in the Scr pattern, because $S c r$ determines cell fate and, therefore; must establish an enduring distinction between cells on either side of its expression border.

In this study and others (S. DiNardo and P. O'Farrell, unpubl.), while mapping expression domains for various genes or their expression levels, distinctions between the ventrolateral and dorsolateral ectodermal regions have been found. Recently, others have noted the sharp transition in neurogenic potential (Hartenstein et al. 1985 ) and in the mitotic division schedule (Hartenstein and Campos-Ortega 1985; V. Foe, pers. comm.) in this region of the ectoderm. It is possible that the positional restriction in all of these phenomena maps to the same precise border along the dorsoventral axis and that the genes that affect dorsoventral positional information establish this border.

\section{Transitions in homeotic protein patterns may be due to} cross-regulatory interactions

As each class of segmentation genes becomes active, interactions among the genes of that class presumably lead to changes in the expression patterns or to maintenance of the initial patterns. Similarly, it is likely that changes in the homeotic protein patterns observed during development reflect regulatory interactions among the homeotic genes. For example, in the absence of $U b x$ function, Antp is expressed at a high level not only in its usual PS 4 position but also in PS 5 and PS 6 (Hafen et al. 1984; Harding et al. 1985; Carroll et al. 1986). PS 5 and PS 6 are places where $U b x$ is normally expressed. Thus, $U b x$ is formally a negative regulator of Antp. However, the initial pattern of Antp transcription is normal in a $U b x^{-}$embryo (Harding et al. 1985) and is established before significant amounts of $U b x$ protein accumulate. The action of $U b x$ on Antp is to prevent Antp products from reaching high levels in PS 5 and PS 6 . The level of Antp expression decreases laterally in $\mathrm{pT} 2$ and $\mathrm{pT} 3$ during germ-band shortening (Fig. 4e,f) in exactly the places where $U b x$ protein accumulates. This effect involves an alteration in Antp expression, not the maintenance of an existing pattern, and is presumably accomplished by a build-up of $U b x$ protein, which then negatively regulates Antp.

The genetic dissection of homeotic gene function has shown that particular structures within a segment can depend on different genetic subfunctions of a gene (Lewis 1978). Recent molecular analyses of these genes has indicated that some such subfunctions may be cisacting control elements that activate the homeotic gene in a particular subset of cells in a segment (Beachy et al. 1985; Bender et al. 1985; Hogness et al. 1985; White and Wilcox 1985b; Lipshitz et al. 1987; Peifer et al. 1987). It is clear that homeotic genes can be expressed in small, precisely localized groups of cells within segments, as is shown by the complexities in the patterns of Scr, Antp, and $U b x$. The control of the fine details of segmental patterning by homeotic genes probably depends in part on these subsegmental (and subcompartmental) complexities in spatial expression.

\section{The possibilities for combinatorial gene action}

It has been proposed that pair-rule segmentation genes carry out their role in a combinatorial manner (Gergen et al. 1986). The relationship described here in molecular terms between developing en expression and the $\mathrm{ftz}$ pattern suggests the combinatorial control of $e n$. It has been shown previously that $f t z$ activity is necessary for the production of even-numbered en stripes (Howard and Ingham 1986; DiNardo and O'Farrell 1987). Here, 
we have shown that en is expressed in only the first of about four (and then three) rows of cells that express $f t z$; therefore, $f t z$ is not sufficient for en induction. Some other factors must distinguish the first row of $f t z-e x-$ pressing cells for these to uniquely induce $e n$. It is quite probable that some of these factors are other pair-rule gene products, such as those of odd-skipped, whose striped distribution partly overlaps ftz stripes (D. Coulter and E. Wieschaus, pers. comm.) and whose activity is required to prevent en expression in the more posterior cells of a ftz stripe (DiNardo and O'Farrell 1987).

A second type of combinatorial control mechanism involves the interaction of multiple gene products within a single cell. The action of homeotic genes may also be combinatorial, the fate of a segment being determined by the array of genes active there (Lewis 1978; Struhl 1982; Kaufman and Abbott 1984). Because many cells within a segment often produce the same homeotic protein and yet develop differently, there must be more genes involved in the elaboration of segmental patterns than simply the homeotic products studied here. One possibility is that differences in expression of segment polarity genes could cause cells that contain the same homeotic protein (or same set of them) to behave differently. For example, $U b x$ would have a different effect on pT3 cells than on aA1 cells, not only because en lowers $U b x$ transcription in $\mathrm{pT} 3$ but also because the en protein interacts in some way with $U b x$ protein (or a target of $U b x$ protein) to modulate the effect of $U b x$. There are many segment polarity genes (at least nine), and they may act throughout development in different cells within each segment. It will be important to examine further the interactions of segment polarity genes with homeotic genes in controlling the development of segmental pattern.

How could the different genes interact? The experiments reported here demonstrate that more than one of the regulatory genes studied can be expressed in the same cell at the same time. ftz, en, Scr, Antp, and Ubx all encode nuclear proteins that contain homeo domains (McGinnis et al. 1984; Scott and Weiner 1984; Harding et al. 1985; Laughon et al. 1985; Kuroiwa et al. 1985; Poole et al. 1985), a conserved 60-amino-acid sequence. The homeo domain has structural similarity to a class of bacterial DNA-binding proteins (Laughon and Scott 1984) and to the products of the yeast MAT locus (Shepherd et al. 1984) which encodes sequence-specific DNAbinding proteins that regulate transcription (Johnson and Herskowitz 1985). The en homeo domain has been shown to be capable of sequence-specific DNA binding in vitro (Desplan et al. 1985), as has the $f t z$ homeo domain (C. Desplan and P.H. O'Farrell; A. Laughon and M.P. Scott, both unpubl. data). Previously, we have discussed models for combinatorial action in which multiple homeo domain-containing proteins in the same cell form heterodimers that have different DNA-binding specificity than either homodimer (Desplan et al. 1985; Laughon et al. 1985). Such a model, based on models for yeast MAT function (Miller et al. 1985), presupposes the occurrence of cells in which multiple homeo domain proteins are expressed, examples of which are demonstrated here (see also Carroll et al. 1986).

The results illustrate the value of single-cell resolution studies on the spatial expression of segmentation and homeotic genes. Much of what remains to be learned about early embryonic gene interactions will build from precise descriptions of the relationships between the patterns of expression of different genes. The goal is to understand the exact correspondence between the temporal and spatial aspects of pattern-forming expression and the regulatory mechanisms used during oogenesis and embryogenesis to control them.

\section{Materials and methods}

\section{Antibodies}

The rabbit anti-ftz (Carroll and Scott 1985), rabbit anti-Antp (Carroll et al. 1986), rabbit anti-Scr (Riley et al. 1987), rabbit anti-en (DiNardo et al. 1985), and mouse monoclonal anti-Ubx; (White and Wilcox 1984) antibodies have all been described previously. The polyclonal mouse anti-en antibody was produced and affinity purified in a manner similar to the corresponding rabbit antiserum (S. DiNardo and P. O'Farrell, unpubl.). The $S c r$ monoclonal antibody was generously provided by Marcie Glicksman and Danny Brower (University of Arizona, Tucson). All polyclonal antibodies were affinity purified.

Secondary antibodies were either rhodamine- or fluoresceinconjugated affinity-purified goat or sheep anti-rabbit Ig and anti-mouse Ig reagents from Cappel and Boehringer-Mannheim.

\section{Immunofluorescence}

Whole-mount embryos were fixed, stained, and photographed as described previously (Carroll and Scott 1985; DiNardo et al. 1985). Double labeling was performed with the following combinations of antibodies: rabbit anti-ftz/mouse anti-en; rabbit anti-en/monoclonal anti-Ubx; rabbit anti-Scr/mouse anti-en; rabbit anti-Antp/monoclonal anti-Ubx; rabbit anti-Antp/ mouse anti-en. Triple labeling was performed with mouse anti$S C r$ and anti-Ubx and rabbit anti-Antp. Embryos were mounted in $50 \mathrm{mM}$ Tris $-\mathrm{HCl}(\mathrm{pH} 8.8)$ containing $10 \%$ glycerol (vol/vol) and $5 \mathrm{mg} / \mathrm{ml} \mathrm{p}$-phenylenediamine and photographed using Tri-X-film, ASA 400 (Kodak).

\section{Acknowledgments}

We thank Drs. Danny Brower and Marcie Glicksman for providing the Scr monoclonal antibody; Drs. John Tamkun and Chris Doe for critical review of the manuscript; and Dr. Peter Lawrence for communication of results prior to publication. This work was supported by a National Institutes of Health (NIH) fellowship GM-09756 to S.B.C., and Lucille P. Markey Fellowship to S.D., NIH grants GM-37193 and GM-31286 and National Science Foundation grant DCD8418016 to P.H.O., and, NIH grant HD-18163 to M.P.S. We also acknowledge a Searle Scholar Award to M.P.S., and an MRC Project Grant and a Nuffield Foundation Award to R.A.H.W. Thanks to Cathy S. Inouye for preparing the manuscript.

\section{References}

Akam, M. 1987. The molecular basis for metameric pattern in the Drosophila embryo. Development 101: 1-22.

Akam, M.E. and A. Martinez-Arias. 1985. The distribution of 
Ultrabithorax transcripts in Drosophila embryos. EMBO I. 4: $1689-1700$.

Anderson, K.V. and C. Nüsslein-Volhard. 1984. Information for the dorsal-ventral pattern of the Drosophila embryo is stored as maternal mRNA. Nature 311: 223-227.

Baker, N.E. 1987. Molecular cloning of sequences from wingless, a segment polarity gene in Drosophila: The spatial distribution of a transcript in embryos. EMBO J. 6: 1765-1773.

Beachy, P.A., S.L. Helfand, and D.S. Hogness. 1985. Segmental distribution of bithorax complex proteins during Drosophila development. Nature 313: 545-551.

Bender, W., B. Weiffenbach, F. Karch, and M. Peifer. 1985. Domains of cis-interaction in the bithorax complex. Cold Spring Harbor Symp. Quant. Biol. 50: 173-180.

Bopp, D., M. Burri, S. Baumgartner, G. Frigerio, and M. Noll. 1986. Conservation of a large protein domain in the segmentation gene paired and in functionally related genes of Drosophila. Cell 47: 1033-1040.

Carroll, S.B. and M.P. Scott. 1985. Localization of the fushi tarazu protein during Drosophila embryogenesis. Cell 43: 47-57.

Carroll, S.B., R.A. Laymon, M.A. McCutcheon, P.D. Riley, and M.P. Scott. 1986. The localization and regulation of Antennapedia protein expression in Drosophila embryos. Cell 47: 113-122.

Desplan, C., J. Theis, and P.H. O'Farrell. 1985. The Drosophila developmental gene, engrailed, encodes a sequence-specific DNA binding activity. Nature 318: 630-635.

DiNardo, S. and P.H. O'Farrell. 1987. Establishment and refinement of segmental pattern in the Drosophila embryo: spatial control of engrailed expression by pair-rule genes. Genes Dev. 1: 1212-1225.

DiNardo, S., J.M. Kuner, J. Theis, and P.H. O'Farrell. 1985. Development of embryonic pattern in $\mathrm{D}$. melanogaster as revealed by accumulation of the nuclear engrailed protein. Cell 43: 59-69.

Duncan, I.M. 1986. Control of bithorax complex functions by the segmentation gene fushi tarazu of Drosophila melanogaster. Cell 47: 297-309.

Gergen, J.P., D. Coulter, and E. Wieschaus. 1986. Segmental pattern and blastoderm cell identities. Symp. Soc. Devel. Biol. 44: 195-220.

Hafen, E., M. Levine, and W.J. Gehring. 1984. Regulation of Antennapedia transcript distribution by the bithorax complex in Drosophila. Nature 307: 287-289.

Harding, K., C. Wedeen, W. McGinnis, and M. Levine. 1985. Spatially regulated expression of homeotic genes in Drosophila. Science 229: 1236-1242.

Hartenstein, V. and J.A. Campos-Ortega. 1985. Fate-mapping in wild-type Drosophila melanogaster. I. The spatio-temporal pattern of embryonic cell divisions. Wilhelm Roux's Arch. Dev. Biol.194: 181-195.

Hartenstein, V., G.M. Technau, and J.A. Campos-Ortega. 1985. Fate-mapping in wild-type Drosophila melanogaster. III. A fate map of the blastoderm. Wilhelm Roux's Arch. Dev. Biol. 194: 213-216.

Hiromi, Y., A. Kuroiwa, and W.J. Gehring. 1985. Control element of the Drosophila segmentation gene fushi tarazu. Cell 43: 603-613.

Hogness, D.S., H.D. Lipshitz, P.A. Beachy, D.A. Peattie, R.A. Saint, M. Goldschmidt-Clermont, P.J. Harte, E.R. Gavis, and S.L. Helfand. 1985. Regulation and products of the $U b x$ domain of the bithorax complex. Cold Spring Harbor Symp. Quant. Biol. 50: 181-194.

Howard, K. and P. Ingham. 1986. Regulatory interactions between the segmentation genes fushi tarazu, hairy, and engrailed in the Drosophila blastoderm. Cell 44: 949-957.
Ingham, P.W. and A. Martinez-Arias. 1986. The correct activation of Antennapedia and bithorax complex genes requires the fushi tarazu gene. Nature 324: 592-597.

Johnson, A.D. and I. Herskowitz. 1985. A repressor (MATa2) product and its operator control expression of a set of celltype specific genes in yeast. Cell 42: 237-247.

Jürgens, G., E. Wieschaus, C. Nüsslein-Volhard, and H. Kluding. 1984. Mutations affecting the pattern of the larval cuticle in Drosophila melanogaster. II. Zygotic loci on the third chromosome. Wilhelm Roux's Arch. Dev. Biol. 193: 283-295.

Karr, T.L. and B.M. Alberts. 1986. Organization of the cytoskeleton in early Drosophila embryos. $/$. Cell Biol. 102: 14891504.

Kaufman, T.C. and M.K. Abbott. 1984. Homoeotic genes and the specification of segmental identity in the embryo and adult thorax of Drosophila melanogaster. In Molecular aspects of early development (ed. G.M. Malacinski and W.H. Klein), pp. 189-218, Plenum Press, New York.

Kornberg, T. 1981a. Compartments in the abdomen of Drosophila and the role of the engrailed locus. Dev. Biol. 86: 363381.

- 1981b. engrailed: A gene controlling compartment and segment formation in Drosophila. Proc. Natl. Acad. Sci. 78: 1095-1099.

Kuroiwa, A., U. Kloter, P. Baumgartner, and W.J. Gehring. 1985. Cloning of the homeotic Sex combs reduced genes in Drosophila and in situ localization of its transcripts. EMBO I. 4: 3757-3764.

Laughon, A. and M.P. Scott. 1984. Sequence of a Drosophila segmentation gene: Protein structure homology with DNAbinding proteins. Nature 310: 25-31.

Laughon, A., S.B. Carroll, F.A. Storfer, P.D. Riley, and M.P. Scott. 1985. Common properties of proteins encoded by the Antennapedia complex genes of Drosophila melanogaster. Cold Spring Harbor Symp. Quant. Biol. 50: 253-262.

Lawrence, P.A., P. Johnston, P. MacDonald and G. Struhl. 1987. Borders of parasegments in Drosophila embryos are delimited by the fushi tarazu and even-skipped genes. Nature 328: 440-442.

Lewis, E.B. 1978. A gene complex controlling segmentation in Drosophila. Nature 276: 565-570.

Lipshitz, H.D., D.A. Peattie, and D.S. Hogness. 1987. Novel transcripts from the Ultrabithorax domain of the bithorax complex. Genes Dev. 1: 307-322.

Mahaffey, J.W. and T.C. Kaufman. 1987. Distribution of the Sex combs reduced gene products in Drosophila melanogaster. Genetics 117: $51-60$.

Martinez-Arias, A. and P.A. Lawrence. 1985. Parasegments and compartments in the Drosophila embryo. Nature 313: 639642.

Martinez-Arias, A., P.W. Ingham, M.P. Scott, and M.E. Akam. 1987. The spatial and temporal deployment of Dfd and Scr transcripts throughout development of Drosophila. Development 100: 673-683.

McGinnis, W., M. Levine, E. Hafen, A. Kuroiwa, and W.J. Gehring. 1984. A conserved DNA sequence in homeotic genes of the Drosophila Antennapedia and bithorax complexes. Nature 308: 428-433

Miller, A.M., V.L. McKay, and K.A. Nasmyth. 1985. Identification and comparison of two sequence elements that confer cell-type specific transcription in yeast. Nature 314: 598602.

Morata, G., and P.A. Lawrence. 1975. Control of compartment development by the engrailed gene in Drosophila. Nature 255: 614-617.

Nüsslein-Volhard, C. and E. Wieschaus. 1980. Mutations af- 


\section{Carroll et al.}

fecting segment number and polarity in Drosophila. Nature 287: 795-801.

Peifer, M., F. Karch, and W. Bender. 1987. The bithorax complex: control of segmental identity. Genes Dev. 1: 891-898.

Poole, S.J., L. Kauvar, B. Drees, and T. Kornberg. 1985. The engrailed locus of Drosophila: Structural analysis of an embryonic transcript. Cell 40: 37-43.

Riley, P.D., S.B. Carroll, and M.P. Scott. 1987. The localization and regulation of Sex combs reduced protein in Drosophila embryos. Genes Dev. 1: 716-730.

Sato, T., P.J. Hayes, and R.E. Denell. 1985. Homoeosis in Drosophila: Roles and spatial patterns of expression of the $A n$ tennapedia and Sex combs reduced loci in embryogenesis. Dev. Biol. 111: 171-192.

Scott, M.P. and S.B. Carroll. 1987. The segmentation and homeotic gene network in early Drosophila development. Cell 51: 689-698.

Scott, M.P. and A.J. Weiner. 1984. Structural relationships among genes that control development: Sequence homology between the Antennapedia, Ultrabithorax, and fushi tarazu loci of Drosophila. Proc. Natl. Acad. Sci. 81: 4115-4119.

Shepherd, J.C.W., W. McGinnis, A.E. Carrasco, E.M. De Robertis, and W.J. Gehring. 1984. Fly and frog homoeodomains show homologies with yeast mating type regulatory proteins. Nature 310: 70-71.

Struhl, G. 1982. Genes controlling segmental specification in the Drosophila thorax. Proc. Natl. Acad. Sci. 79: 73807384.

Wakimoto, B.T. and T.C. Kaufman. 1981. Analysis of larval segmentation in lethal genotypes associated with the Antennapedia gene complex in Drosophila melanogaster. Dev. Biol. 81: 51-64.

Weir, M.P. and T. Kornberg. 1985. Patterns of engrailed and fushi tarazu transcripts reveal novel intermediate stages in Drosophila segmentation. Nature 318: 433-439.

White, R.A.H. and R. Lehmann. 1986. A gap gene, hunchback, regulates the spatial expression of Ultrabithorax. Cell 47: $311-321$.

White, R.A.H. and M. Wilcox. 1984. Protein products of the bithorax complex in Drosophila. Cell 39: 163-171.

1985a. Distribution of Ultrabithorax proteins in Drosophila. EMBO I. 4: 2035-2043.

- 1985b. Regulation of the distribution of Ultrabithorax proteins in Drosophila. Nature 318: 563-567.

Wirz, J., L.I. Fessler, and W.J. Gehring. 1986. Localization of the Antennapedia protein in Drosophila embryos and imaginal discs. EMBO J. 5: 3327-3334. 


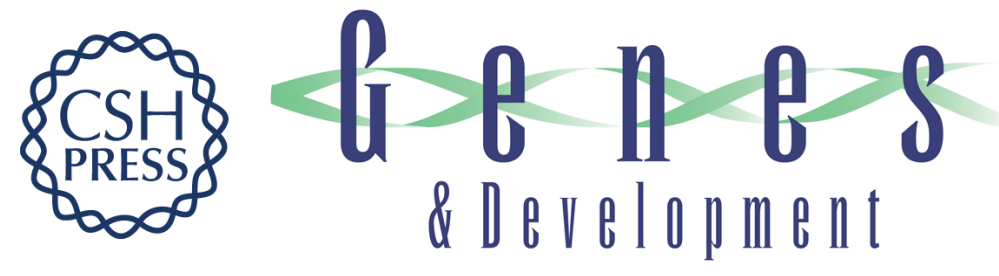

\section{Temporal and spatial relationships between segmentation and homeotic gene expression in Drosophila embryos: distributions of the fushi tarazu, engrailed, Sex combs reduced, Antennapedia, and Ultrabithorax proteins.}

S B Carroll, S DiNardo, P H O'Farrell, et al.

Genes Dev. 1988, 2:

Access the most recent version at doi:10.1101/gad.2.3.350

References This article cites 55 articles, 14 of which can be accessed free at: http://genesdev.cshlp.org/content/2/3/350.full.html\#ref-list-1

License

Email Alerting Service

Receive free email alerts when new articles cite this article - sign up in the box at the top right corner of the article or click here.

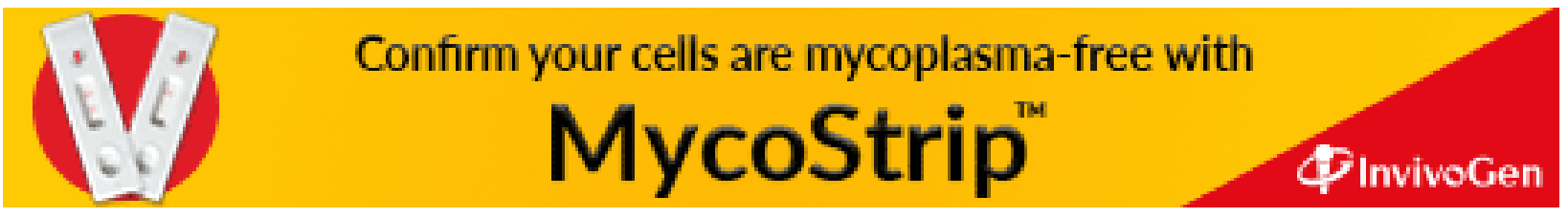

